\title{
Cultura, mobilidade e direitos humanos: reflexóes sobre terapia ocupacional social no contexto da política municipal para população imigrante
}

\author{
Miki Takao Sato ${ }^{\mathrm{a}, \mathrm{b}}$, Denise Dias Barros ${ }^{\mathrm{a}, \mathrm{b}, \mathrm{c}}$ \\ ${ }^{a}$ Casa das Áfricas, Núcleo Amanar, São Paulo, SP, Brasil. \\ 'Programa de Pós-graduação em Terapia Ocupacional, Universidade Federal de São Carlos - UFSCar, \\ São Carlos, SP, Brasil. \\ 'Projeto METUIA, Programa de Pós-graduação Interunidades de Estética e História da Arte, \\ Universidade de São Paulo - USP, São Paulo, SP, Brasil.
}

\begin{abstract}
Resumo: O objetivo do presente artigo é problematizar a necessidade de revisão da formação e da ação profissional, no contexto da terapia ocupacional social, diante do fenômeno crescente da migração internacional, particularmente na atual construção da política municipal para populações imigrantes na cidade de São Paulo, SP. Metodologicamente, a discussão articula-se em três eixos complementares de resultados de análise a partir de pesquisa documental acompanhada de estudo de campo, visitas, participação em reuniões, fóruns interinstitucionais, audiências públicas, debates temáticos, além de revisão da literatura. No primeiro eixo de análise, contextualiza-se a legislação vigente no Brasil, a construção da política de migração em âmbito municipal e as articulações da sociedade civil frente à mobilidade humana, compreendida como direito fundamental. No segundo, discutem-se serviços de atenção a pessoas, famílias e grupos em situação migratória no município de São Paulo, SP. Finalmente, no terceiro eixo, discutem-se os desdobramentos da cultura na terapia ocupacional social para a ação profissional e formação no campo da mobilidade humana. Como resultado, observou-se que esse panorama atual coloca novos desafios profissionais, obrigando o terapeuta ocupacional a rever sua posição técnico-política diante novas realidades da contemporaneidade.
\end{abstract}

Palavras-chave: Migração, Direitos Humanos, Terapia Ocupacional Social, Políticas Públicas, Cultura.

\section{Culture, mobility and human rights: considerations on social occupational therapy in the context of immigrants municipal policy}

\begin{abstract}
This article aims to discuss the need to revise education and professional action, in the context of social occupational therapy, facing the growing phenomenon of international migration, especially in the current construction of the municipal policy for immigrant populations in São Paulo, SP. The discussion is methodologically structured into three complementary lines of analysis results from documentary research accompanied by field study, visits, participations in meetings, inter-institutional forums, public hearings, thematic debates, in addition to literature review. In the first analysis axis, we discuss the current legislation in Brazil, the construction of migration policy at the municipal level and civil society articulations about human mobility, understood as a fundamental right. In the second, we discuss people care services, families and groups in migratory situation in São Paulo, SP. Finally, on the third axis, we discuss the cultural developments in social occupational therapy for professional action and training in the field of human mobility. As a result it was observed that the current panorama poses new professional challenges, forcing the occupational therapist to review its technical-political position face to the new realities of the contemporary world.
\end{abstract}

Keywords: Migration, Human Rights, Social Occupational Therapy, Public Politics, Culture.

Autor para correspondência: Miki Takao Sato, Casa das Áfricas, Rua Harmonia, 1150, Vila Madalena, CEP 05435-001, São Paulo, SP, Brasil, e-mail: mikitsato@gmail.com

Recebido em Maio 30, 2015; Revisão em Out. 27, 2015; Aprovado em Nov. 23, 2015. 


\section{Introdução}

O fenômeno da migração tem ganhado destaque e contornos complexos a partir das transformações sociais, políticas, culturais e econômicas nas últimas décadas, culminando com processos mundiais de mobilidade humana. Há, assim, intensa mobilização devido à geopolítica e a interesses das grandes potências e corporaçôes, em grande parte responsáveis, direta ou indiretamente, por guerras, crises econômicas, conflitos políticos e religiosos, catástrofes naturais (TELES, 2013), além da intensificação de conflitos armados com grande impacto sobre a populaçáo civil ${ }^{1}$. Estes fatores, entre outros, são, por um lado, raízes da migração como busca de sobrevivência ou de busca de oportunidades. Por outro, geraram a necessidade da institucionalização do Direito Internacional Humanitário, do Direito Internacional dos Direitos Humanos e a consolidaçáo do Comitê Internacional da Cruz Vermelha (KRIEGER, 2002).

Contudo, as contradiçóes e paradoxos avolumam-se. Embora a livre circulação de pessoas seja princípio garantido pela Declaraçáo Universal dos Direitos do Homem da Organização das Naçôes Unidas (ORGANIZAÇÃO..., 2009), ainda permanece como um dos grandes desafios contemporâneos (COHEN, 1999; SAYAD, 1998). O cenário mundial da mobilidade humana tem sido objeto de reflexão e açôes de enfrentamento em vários campos de atuação e conhecimento. Nesse âmbito, a terapia ocupacional tem, por meio de diversos/as pesquisadores/as, contribuído com estudos e reflexôes sobre esta importante questão contemporânea.

A recente construção da política de migração em âmbito municipal - em grande parte apoiada na sociedade civil - orientada pela garantia de direitos humanos em Sáo Paulo forma a base empírica do estudo e discussôes do presente artigo. Nesse novo contexto de intensificação da mobilidade internacional para o Brasil, desvela-se, ao mesmo tempo, a importância de estudos no campo da terapia ocupacional social para a revisão da formação e da ação profissional diante de sua forte implicação nas dinâmicas dos diálogos interculturais e para a compreensão das atividades significativas em suas movências de linguagens e sentidos. A migração atual é um dos fatores que tem evidenciado conflitualidades persistentes no país (racismo, sexismo e intolerância religiosa) e criado novos desafios frente a expressóes de xenofobia e à desqualificação estética e linguística não hegemônicas, marcando de forma profunda a percepção e a compreensão das atividades e do fazer na vida social, econômica e cultural. Por isso, faz-se necessário deter-se na reflexão sobre formação e consolidação de estereótipos e preconceitos ligados à mobilidade humana com suas novas formas de relações de alteridade, sendo fundamental reflexão para diversas especialidades da ação em terapia ocupacional. Metodologicamente, cabe assinalar que a discussão se organiza a partir de pesquisa documental, acompanhada de estudo de campo -- realizado entre janeiro e setembro de 2015 - com visitas a instituiçóes e participação em reunióes, audiências públicas, conferências, fóruns interinstitucionais, e debates temáticos vinculados à política migratória brasileira e, sobretudo, pertinentes à política municipal em construçáo na capital paulista.

Os argumentos neste artigo articulam-se em torno da noção de cultura como necessidade básica e direito fundamental (UNESCO, 2002) em três eixos complementares. No primeiro, contextualiza-se a política migratória com seus desafios atuais; no segundo, discutem-se os serviços e a atenção a pessoas, famílias ou grupos em situação migratória no município de São Paulo. Finalmente, no terceiro eixo trabalham-se - com base nas reflexôes mais recentes em terapia ocupacional social no Brasil - as conexóes fundamentais ligadas às dinâmicas culturais em situaçóes de coabitação da diferença e aos espaços de significaçáo (BARROS et al., 2013) construídos no interior da mobilidade humana. Pretende-se, assim, contribuir para a construção de ações de políticas públicas pautadas nos direitos humanos, balizando a formaçấo e as açôes em terapia ocupacional, sobretudo do campo social. Desse modo, a noção de cultura como direito complementa-se, neste estudo, com a reflexão sobre as atividades na experiência da migração. Estas, culturalmente móveis e abertas, correspondem a práticas históricas, estéticas e culturais diferenciadas que erguem espaços de significação criativos e plurais nos entrelaçamentos de linguagens, de expressóes e de modos de fazer. As atividades são gestadas em redes de sentidos e conhecimentos, ao mesmo tempo, geram novos circuitos e redes relacionais e são capazes de mobilizar articulaçóes entre cultura, arte, economia e política.

\section{Situando a atual imigração no Brasil}

Ao resgatar o processo histórico contemporâneo dos fenômenos migratórios no Brasil, Neide Patarra (2012) mostra que a partir de 1930, com a crise econômica mundial de 1929, inicia-se uma política de restrição à entrada de estrangeiros, que até entáo supriam grande parte da necessidade de mão de obra no país agrícola. Esse cenário manteve-se 
estabilizado até a década de 1980, comum processo de migração interna (de estados do Nordeste para Sudeste e Sul) e, concomitantemente, com a crise econômica brasileira da década de 1980, intensificou-se o processo inverso de emigração, com grande saída de brasileiros dirigindo-se principalmente aos Estados Unidos, Japão, Europa e, em menor escala, Paraguai (PATARRA, 2012; SOARES; LOBO; MATOS, 2015).

A partir dos anos 2000, o Brasil (e também outros países em desenvolvimento) intensificou novamente a entrada de estrangeiros de países como Coreia do Sul, China, países africanos e latino-americanos (PATARRA, 2012), resultado inclusive do endurecimento das políticas migratórias internacionais e o fechamento das fronteiras da Europa e dos Estados Unidos. É importante destacar que, a partir das décadas de 1980 e 1990, o Brasil recebeu um grande número de pessoas oriundas de países africanos em decorrência dos processos de lutas de independência e conflitos pós-coloniais (SERRANO, 2011).

Os processos migratórios sempre ocorreram de maneira bastante diversa, em função da complexidade da globalização, política econômicas, sociais e migratórias (internacional e brasileira). Serrano (2011) revela que, além da migração motivada por fatores econômicos, presencia-se a vinda de trabalhadores qualificados, estudantes de graduação e pós-graduação através de convênios e cooperação internacional, pessoas vítimas de tráfico humano, solicitantes de refúgio, entre outros. A partir de 1961, firmou-se no país a abertura de várias embaixadas e representaçôes de países africanos, possibilitando convênios e acordos de cooperação cultural, técnica e acadêmica, permitindo que muitos estudantes viessem a estudar nas universidades brasileiras (KALY, 2001).

A cidade de São Paulo acompanhou esses processos migratórios nacionais, e foi a partir dos anos 1970 que houve uma entrada significativa de estrangeiros, notadamente de países da América do Sul, principalmente bolivianos, peruanos e paraguaios (PAIVA, 2012), que se intensifica a partir dos anos 2000 de maneira expressiva. Recentemente, desde 2010, São Paulo recebe em grandes proporçôes africanos de diversos países, haitianos e sírios.

Nesse sentido, tanto o Brasil quanto a cidade de Sáo Paulo têm buscado diferentes formas de dialogar com essa nova dinâmica cultural, econômica e social, já que a cidade tem se tornado importante destino de fluxos migratórios internacionais. Há atualmente cerca de um milhão de estrangeiros em situação regular no país, com 386 mil destes na capital paulista. Estimam-se ainda aproximadamente 185 mil estrangeiros em situação irregular na cidade (OESTRANGEIRO, 2014), além de cerca de 25 mil solicitantes de refúgio, dentre os quais apenas 7 mil reconhecidos pelo governo brasileiro (REDEBRASILATUAL, 2015). Embora a proporção numérica seja pequena em relação à escala mundial, é notório o aumento significativo da presença de novos imigrantes na capital paulista (NAIME, 2006).

Segundo Jéssica Naime (2006), vários são os motivos que mobilizam a migração: fatores econômicos, busca por melhores condições de vida, crises gerando grande número de refugiados, a busca de possibilidades para a educação, formação acadêmica e profissional. Cabe ressaltar que, apesar de a lei de migração brasileira ser restritiva e pautada na segurança nacional, a legislação de refúgio abre possibilidades para toda pessoa que chega em território nacional solicitar o estatuto de refúgio. É importante lembrar, igualmente, que o Brasil integra em nossos dias o circuito do tráfico humano (BRASIL, 2013b), e que houve, após a queda do muro de Berlim, o enrijecimento das fronteiras europeias e dos Estados Unidos da América. Além disso, sabe-se, igualmente, que grande parcela das pessoas que migram expóem-se a diversas formas e dinâmicas de violaçáo de direitos humanos, deparando-se com a frequente falta de informação e de assistência, além das crescentes situaçóes de racismo e xenofobia (KALY, 2001).

Vigora no Brasil o marco legal balizado pela Lei no 6.815 de 1980, conhecida como Estatuto do Estrangeiro (BRASIL, 1980). A legislação foi estabelecida no contexto da ditadura militar, com uma concepção de segurança nacional e criminalização da migraçáo, em que o estrangeiro era visto como ameaça à ordem brasileira (BONASSI, 1998). Mesmo diante da importância dos imigrantes para a economia e para dinâmica histórica e cultural do Brasil, esta perspectiva tem dificultado a vida de milhares de pessoas que se veem desprotegidas e vivendo constantes violaçóes de direitos fundamentais (PISCITELLI, 2008). O contato inicial e as demandas solicitadas por qualquer estrangeiro ao ingressar no país é responsabilidade da Polícia Federal, prevalecendo uma abordagem de segurança e repressão, com pouca possibilidade de regularização migratória e mesmo de permanência no país, seja para que vem para trabalhar, morar ou até mesmo estudar. Por exemplo, o estrangeiro, ainda que em situação regular, não tem direito a voto e a liberdade de expressão, e de associar-se politicamente, além de dificuldades para validação de diplomas de graduaçáo e concessão de vistos para estudantes. O imigrante depara-se com a dificuldade na legalização do Registro Nacional 
de Estrangeiro (RNE) ou na obtenção do estatuto de refugiado, problemáticas de acesso a serviços, burocracias, grandes ônus econômicos com documentação, situaçóes de preconceito, barreiras no acesso aos serviços de saúde e de assistência e desconhecimento dos profissionais. Percebe-se uma reprodução da lógica do estrangeiro como ameaça e sujeitos sem direitos na realidade de alguns serviços que atuam direta ou indiretamente com a questão.

Entretanto, o panorama atual do fenômeno das migraçôes internacionais cria novas dinâmicas para se lidar com essas questóes, e diante da rigidez da legislação, da dificuldade de inserção dos estrangeiros e do aumento do número de pessoas que chegam ao país, o Brasil vem debatendo e revendo tanto sua legislação quanto as políticas voltadas para a questáo. Diante disso, coletivos de imigrantes e movimentos ligados aos direitos humanos discutem e lutam para a aprovação do Projeto de Lei da Migração no 288 de 2013, atualmente aprovado pela Comissão de Relaçôes Exteriores do Senado Federal e em tramitação na Câmara dos Deputados. Com essa nova perspectiva, propóe-se uma mudança da concepçáo do estrangeiro como ameaça nacional e problema para um paradigma de sujeito de direitos e de cidadania (BRASIL, 2013a).

Pelo projeto de Lei do Senado (BRASIL, 2013a), a política migratória combaterá situações de xenofobia, discriminação e racismo e a descriminalização dos processos migratórios. Propóe também acolhida humanitária, açóes de desenvolvimento econômico, cultural, social e científico, garantia à reunião familiar e igualdade de direitos dos migrantes perante os brasileiros.

\section{A sociedade civil e a construção da política municipal de populações migrantes em São Paulo}

Historicamente, a cidade de São Paulo tem sido destino importante de pessoas oriundas de diversas regiōes do país e do mundo. Com o adensamento e complexidade do fenômeno, já há alguns anos a cidade vem debatendo e repensando novas formas de lidar com a situação. Vários atores da sociedade civil, do poder público e de movimentos e coletivos têm realizado esforços de discutir e construir políticas públicas voltadas para questão da imigração, que precisa ser compreendida como parte do debate sobre Direitos Humanos Fundamentais. Sua complexidade e amplitude passou a exigir a construção de política específica, além da revisão e transformação dos marcos legais que regem a imigração no país.

É essencial ressaltar que essa política municipal para a questão da imigração foi construída por esforços conjuntos e, principalmente, a partir da mobilização da própria população migrante, que notadamente deparava-se com situaçóes de discriminação, xenofobia, acesso precário aos serviços de saúde, educação e moradia, dificuldades nas questóes jurídicas e de inserção laboral de pessoas de origens diferentes (sobretudo latino-americanos, asiáticos e africanos de diversas nacionalidades e apátridas). Assim, esses grupos foram criando iniciativas de organização e redes de apoio para as mais diversas demandas coletivas (culturais, linguísticas, jurídicas, religiosas), e através desses novos arranjos coletivos foram inserindo-se em espaços de interlocução com as secretarias públicas, mobilizando outros atores $\mathrm{da}$ sociedade civil, organizaçôes não governamentais, centros de acolhida, universidades. Desse modo, fizeram-se visíveis na cidade e presentes nas suas reivindicações, forçando uma mobilização coletiva na cidade de Sáo Paulo.

$\mathrm{Na}$ Conferência das Naçóes Unidas de Direitos Humanos, realizada em Viena em 1993, o Brasil assumiu o compromisso de constituir um programa de direitos humanos com ações nacionais, regionais e locais. Dessa forma, o Município passou a ter obrigação de desenvolver política municipal de direitos humanos. Diante desse imperativo, foi instituída a Comissáo Municipal de Direitos Humanos de São Paulo (CMDH-SP), através da Lei Municipal 13.292/2002 (SÃO PAULO, 2002, p. 1). Em seu artigo segundo declara que:

Constituem Direitos Humanos, sob a proteção da Comissão Municipal de Direitos Humanos, os direitos e garantias fundamentais, previstos nas Constituições Federal e Estadual, na Lei Orgânica do Município de São Paulo, na legislação das três esferas e nos tratados e convençôes internacionais de que o Brasil for parte, compreendendo os direitos individuais, coletivos e sociais.

A partir da Comissão iniciaram-se atendimentos e acolhimento de denúncias de violação dos direitos humanos, encaminhamentos e orientaçóes destas, e que com o tempo passou a se chamar "Balcão de Atendimento" (PIEROTE-SILVA, 2014). O Balcâo prioriza o trabalho em equipe multiprofissional dos núcleos jurídicos e sociais, atenção individualizada das demandas e orientação quanto aos direitos de cada pessoa atendida (SẤO PAULO, 2005). Desde então, vem recebendo denúncias de violência contra 
crianças e jovens, idosos, mulheres, queixas do sistema de saúde, de serviços para populaçáo de rua e também denúncias de xenofobia e violaçóes dos direitos de imigrantes e refugiados (SÃO PAULO, 2007). O Balcáo acabou também se tornando referência a questóes ligadas aos direitos humanos de imigrantes na cidade, integrando-se às Redes de Discussão de Políticas para Imigrantes e Refugiados, que discute e articula a rede de serviços e movimentos relacionados à temática (PIEROTE-SILVA, 2014).

$\mathrm{Na}$ atualidade, a CMDH-SP reúne demandas das diversas minorias e grupos em situação de vulnerabilidades, marginalização ou exclusão. Nesse sentido, a mobilização social foi importante para reconhecimento da urgência e complexidade dos processos migratórios enquanto situação potencial de fragilização individual e coletiva que terminam por favorecer violaçóes de direitos.

A Secretaria Municipal de Direitos Humanos e Cidadania da cidade de Sáo Paulo (SMDHC) foi criada em janeiro de 2013, a partir do Decreto Municipal no 53.685. Essa nova pasta uniu a antiga Secretaria de Participação e Parceria (SMPP), a Comissão Municipal de Direitos Humanos e o secretário especial de Direitos Humanos (SEDH).

Algumas atribuiçôes foram realocadas em outras secretarias e a SMDHC instituiu novas coordenações, como a de Políticas para a População em Situação de Rua, de Educação em Direitos Humanos, de Direito à Memória e à Verdade, de Políticas para Migrantes, de Políticas para Crianças e Adolescentes e da Política de Participação Social (SÃO PAULO, 2015c, s/p).

A atual gestáo municipal da SMDHC tem colocado a temática da migraçáo como uma de suas pautas principais de trabalho, criando entáo, a partir da Lei $n^{\circ}$ 15.764, de 27/5/13 (Artigo 242), a Coordenação de Políticas para Migrantes (CPMig), decorrente dos avanços da própria política de Direitos Humanos da capital paulista.

A Coordenação tem como objetivo principal a articulação e efetivação de políticas públicas migratórias de maneira transversa e intersetorial, além de ter papel importante de articulação com movimentos sociais e outros atores do poder público (SÃO PAULO, 2015a). A CPMig tem vários projetos e frentes de trabalho, como centros de acolhidas, programa de facilitaçáo de abertura de conta bancária, capacitação de servidores públicos para atendimento ao migrante, curso de português, ações culturais, mapeamento e articulaçôes com políticas de trabalho e empregabilidade (SÃO PAULO, 2015a).
Através da Secretaria, da Coordenação, de movimentos sociais e instituiçôes ligadas à temática da migração e direitos humanos, a capital paulista vivenciou audiências públicas, encontros, debates $\mathrm{e}$ pré-conferências sobre a pauta. Em 2013, houve a I Conferência Municipal de Políticas para Imigrantes - Somos todos migrantes, marco importante para efetivação dos direitos dos migrantes e início da construção de uma política pública efetiva para a temática. Contou com a participação de 13 secretarias municipais e 14 entidades da sociedade civil.

As propostas discutidas na Conferência foram reunidas em quatro eixos temáticos: o primeiro é a promoçáa e garantia de acesso a direitos sociais e serviços públicos, que prevê a cidadania como conceito central, o acesso à educação, à saúde, combate à violência contra mulher imigrante, a questáo do registro migratório, liberdade de expressão e de acesso à produção cultural. $\mathrm{O}$ segundo eixo refere-se à promoção do trabalho decente, que prevê a fiscalização das condiçôes e dos direitos trabalhistas. O terceiro eixo é a inclusão social e reconhecimento cultural, que propóe integração e a não aculturação dos imigrantes, acesso à informação e promoçáo de açôes sobre diversidade cultural nas escolas e também ensino de português. O último eixo é a legislação federal e politica nacional para as migraçóes e refúgio, que exige a revisão do Estatuto do Estrangeiro e também a participaçáo política e direito a voto aos imigrantes.

A Conferência Municipal é uma conquista importante dos movimentos sociais de imigrantes e sua construção envolveu o esforço e dedicação de diversas pessoas e entidades do governo e da sociedade civil. Espera-se que ela se constitua como marco histórico da mudança de paradigma - da segurança nacional aos direitos humanos - que se iniciou na cidade de Sáo Paulo e que seja o ponto de partida de uma série de conquistas para efetivar a migraçáo como um direito fundamental de todo ser humano (SÃO PAULO, 2013, p. 59).

A realização das conferências municipais e estaduais culminou com a I Conferência Nacional sobre Migraçóes e Refúgio (Comigrar), em 2014, também na cidade de São Paulo. Estes são marcos importantes para a construção de políticas públicas e para a efetivação dos direitos dos imigrantes, que antes eram somente pensadas sob óticas individuais e açóes de alguns grupos e serviços desarticulados e sem um plano de trabalho conjunto.

Uma iniciativa importante da SMDHC, através da CPMig, foi a criação do Centro de Referência e Acolhida para Imigrantes (CRAI). Este foi o primeiro 
serviço municipal criado a partir de esforços conjuntos para a implementação de uma Política Municipal para Migrantes na cidade, com articulação de instituiçôes que trabalham com a temática e a Coordenação de Políticas para Migrantes. Divide-se entre o Centro de Referência e o Centro de Acolhida, localizados no mesmo endereço, no bairro da Bela Vista, regiāo central de São Paulo com grande concentração de imigrantes e de equipamentos sociais para pessoas em situaçáo de rua da cidade.

O serviço busca promover o acesso a direitos e inclusão social, cultural e econômica dos imigrantes por meio de atendimentos especializados (jurídico, social, psicológico, encaminhamentos), da oferta de cursos e oficinas, além do serviço de acolhimento. É um serviço municipal inaugurado em 2014 ligado à Coordenação de Políticas para Migrantes, englobando a Secretaria de Direitos Humanos e Cidadania e a Secretaria de Assistência e Desenvolvimento Social. Tanto o centro de referência como o de acolhida são administrados pelo Serviço Franciscano de Solidariedade (SEFRAS).

O Centro de Acolhida oferece 110 vagas (masculinas, femininas ou crianças), com perfis diversos de pessoas abrigadas: solicitantes de refúgio, imigrantes, pessoas vítimas de tráfico humano, pessoas com visto humanitário (haitianos e sírios). Oferece ainda atividades socioeducativas e uma brinquedoteca. A equipe conta também com um psicólogo, duas assistentes sociais, além de um advogado e equipe de apoio. O CRAI oferece orientação e serviços de regularização de documentação, apoio jurídico, encaminhamentos para saúde, educação, trabalho e outros. É aberto para qualquer imigrante, não necessitando estar vinculado ao centro de acolhida, e conta com atendentes imigrantes, facilitando assim a comunicação com as pessoas atendidas (SÃO PAULO, 2015b).

A pluralidade do fenômeno migratório em São Paulo abarca nacionalidades diversas (com presença significativa dos latino-americanos, africanos, haitianos e sírios), motivos de vinda à cidade (melhores oportunidades de trabalho e de estudo, redes de apoio já sustentadas, solicitaçấo de refúgio, reunião familiar), e esses novos rearranjos familiares, econômicos, culturais e sociais desdobram-se também em uma diversidade de demandas e necessidades.

Assim, a cidade apresenta um panorama plural de serviços, associaçóes, iniciativas individuais e coletivas, movimentos sociais, universidades e vários outros atores que se integram no âmbito das políticas públicas e da sociedade civil. Sáo esforços conjuntos que buscam uma articulação e efetivação de políticas públicas específicas para a migração, e também tem dialogado e se posicionado frente a essa questáo e se preparando para novos desafios da migração contemporânea. A complexidade das questóes inerentes ao fenômeno da migração também vai criando nos serviços necessidades de mudanças, interlocução com novas possibilidades, aprendizados e reconfiguraçóes necessárias e também interessantes.

Alguns centros de acolhida foram mudando seu perfil de trabalho conforme o surgimento de novas demandas. A Missão Paz é um dos serviços de acolhida mais antigos da cidade, localizado no bairro do Glicério, na regiáo central. O complexo da Missão Paz faz parte da Congregação de Missionários Scalabrinianos, segmento da Igreja Católica que tradicionalmente desenvolve trabalho com imigrantes desde o século XIX. Na década de 1940, tinha seu trabalho voltado para os imigrantes recém-chegados à cidade. Logo mais acompanhou a leva de migraçáo de pessoas de outras cidades e, a partir da década de 1970, configuraram-se novos fluxos internacionais, notadamente os sul-americanos, depois africanos e haitianos (LÚCIO, 2015). Com o agravamento da situação mundial e com as novas ondas migratórias de outros países, logo se tornou referência para cidade.

A Missão Paz é composta por quatro grandes núcleos: Casa do Migrante, Centro Pastoral e de Mediação dos Migrantes, Centro de Estudos Migratórios e as paróquias Nossa Senhora da Paz, Latino-Americana e Italiana.

A Casa do Migrante é o serviço de acolhida, abriga 110 pessoas (entre homens e mulheres), com serviços de alimentação, bagageiro, lavanderia, palestras e atividades culturais, encaminhamentos para cursos e aulas de português. O Centro Pastoral e de Mediação dos Migrantes é o núcleo das questóes relacionadas a apoio jurídico, saúde, trabalho, família e educação. O Centro de Estudos Migratórios é responsável pela biblioteca especializada na temática da migração e também publica a Revista Travessia, importante veículo sobre o tema. E, por fim, a Paróquia Nossa Senhora da Paz, que realiza seu trabalho religioso e social no bairro (MISSÃO PAZ, 2015). Além disso, a Missão Paz participa ativamente da rede de movimentos ligados às políticas para imigrantes na cidade. Dado seu histórico e dimensão do seu trabalho, tornou-se uma das principais referências da questão.

O Arsenal da Esperança, SERMIG (Servizio Missionario Giovani), nasceu na Itália, através da iniciativa para promover justiça social, desenvolvimento e solidariedade através da Fraternidade da Esperança. Em Sáo Paulo, o Arsenal foi aberto em 1996, nas mesmas instalaçóes da Hospedaria dos Imigrantes, 
que historicamente abrigou milhares de imigrantes do mundo todo e que depois passou a realizar seu trabalho também com pessoas em situação de rua. O Centro de Acolhida, localizado no bairro do Brás, conta com 1.200 vagas masculinas, oferece cursos de português, encaminhamentos, serviço social e atividades culturais (SERMIG, 2015). Atualmente configura-se também como referência para a população em situaçáo de rua, mas ainda assim recebe grande número de estrangeiros.

Na cidade de São Paulo, a Cáritas é a instituição da sociedade civil (ligada à Igreja Católica) responsável pela assistência aos refugiados e solicitantes de refúgio, designada pelo Alto Comissariado das Naçóes Unidas para os Refugiados (ACNUR), através do Comitê Nacional para Refugiados (CONARE), com sedes em Sáo Paulo e no Rio de Janeiro. O centro de acolhida da Cáritas oferece também orientação jurídica, apoio psicológico e social, encaminhamentos para cursos de português e para outros serviços relacionados a trabalho, educação, saúde e documentação (CÁRITAS..., 2015).

O Centro de Apoio e Pastoral do Migrante (CAMI), fundado em 2005 pelo Serviço Pastoral dos Migrantes, tem o objetivo de promover direitos humanos, cidadania e inserção social aos imigrantes, além de atuação de combate ao trabalho escravo e ao tráfico de pessoas. Realiza atendimentos e orientaçôes jurídicas, trabalho de conscientização cultural, encaminhamentos diversos, aulas de português e cursos, e publica o jornal Nosotros Imigrantes. O CAMI também tem atuação política importante e historicamente tem atuação de referência na comunidade de imigrantes sul-americanos.

O Centro Social Nossa Senhora Aparecida - Associação Palotina faz parte dos projetos da Congregação das Irmãs do Apostolado Católica (Palotinas). Após várias mudanças, em 2006, foi reinaugurado o novo centro de acolhida, com o objetivo de receber e atender especificamente mulheres refugiadas e estrangeiras egressas do sistema penitenciário (ASSOCIAÇÃO..., 2015).

A Casa de Passagem Terra Nova é um centro de acolhida recém-inaugurado em outubro de 2014 pelo governo do estado de Sáo Paulo, através da Secretaria da Justiça e da Defesa da Cidadania e da Secretaria de Estado de Desenvolvimento Social. O serviço é gerenciado pela Coordenação Regional de Obras de Promoção Humana (CROPH), possui 50 vagas para refugiados, imigrantes, vítimas de tráfico humano, famílias. Oferece alimentação acolhida, atendimento social psicológico e jurídico, além de encaminhamentos diversos (SÃO PAULO, 2015d).
As instituiçóes que integram em seus objetivos de intervenção a questão da migração são, em grande parte, açóes sociais da Igreja Católica. Elas criaram ou ampliaram projetos de intervenção assistencial e serviços conveniados com a prefeitura, por meio da rede do sistema único da assistência social (SUAS). Os serviços citados estáo inseridos na rede de assistência da cidade. Entretanto, dada a dinâmica atual do fenômeno migratório, também é possível encontrar iniciativas de grupos e outros setores que, de maneira indireta, estão articulados ou acolhem em parte essas novas demandas sociais.

Este é o caso do Centro de Apoio ao Trabalho e Empreendedorismo (CATe), situado no bairro da Luz, região central da cidade, e que possui um Núcleo da Diversidade. O CATe tem atendentes imigrantes e realiza encaminhamentos e programas específicos. Foi criado a partir da demanda de inserção no trabalho no âmbito de ações de uma política intersetorial de atenção ao migrante.

O Instituto de Reintegração do Refugiado - Adus (INSTITUTO..., 2015) é uma organização não governamental criada em 2010 com equipe composta de voluntários, cujo o objetivo é favorecer a integração tanto de refugiados como de solicitantes de refúgio. Trabalha com programas e açôes de reintegração das pessoas na cidade, encaminhamentos para trabalho, orientação jurídica, açóes culturais, curso de língua portuguesa.

Outra instituição que intervém de maneira significativa na acolhida de imigrantes vindos de diversas regiôes muçulmanas é a Mesquita Bilal Al Habashi, situada no centro da cidade de São Paulo, onde há presença expressiva de africanos/as nas imediaçôes. Como um importante espaço religioso e, também, centro de construção de rede social de suporte, tornou-se referência para os recém-chegados na cidade. A Mesquita desenvolve de maneira intensa e ativa açóes de acolhimento e orientaçôes. Muitas pessoas procuram a Mesquita antes mesmo de irem para centros de acolhidas ou para outros serviços especializados.

Nos últimos anos, o surgimento de várias lideranças reforçou a necessidade de se discutir as açóes em educação, saúde, assistência social, além da luta por direitos políticos, incluindo o de voto. A crescente formação de associaçôes reunidas a partir de nacionalidades, especificidades de situação migratória ou afinidades culturais e religiosas discutem, reivindicam e pressionam o poder público e a sociedade civil de forma organizada para a conquista, ampliação e consolidação de seus direitos coletivos e individuais. 
Assim, esse movimento de articulação e reivindicação foi tomando corpo e ganhou visibilidade em 2013, desde a criação da CPMIg referida anteriormente, as audiências públicas, pré-conferências e conferências sobre migração, debates públicos, elaboração de cartilha do migrante (referência) e inserção dos migrantes em várias esferas da sociedade (espaços e atividades culturais, serviços assistenciais, inserção nas universidades e serviços de saúde). Importante ressaltar que foi um período extremamente rico, intenso e plural que a cidade presenciou, pois conseguiu pela primeira vez debater a questão da migração em uma escala notória.

Em alguns equipamentos de saúde, por exemplo, encontramos programas específicos para os estrangeiros, como a contratação de agentes de saúde de diferentes nacionalidades, atendimentos específicos para refugiados e articulação intersetorial entre os serviços.

Vimos também emergir na cidade várias outras iniciativas, grupos de música de migrantes, eventos e feiras culturais, comércios especializados (artesanato, gastronomia, estética, telefonia), debates acadêmicos, etc., configurando um panorama extremamente múltiplo, mas também complexo e permeado por vários desafios. Assim, é visível a necessidade de se repensar a formação do profissional para a diversidade. Diversidade essa que vai além do fenômeno migratório, mas que também abarque questóes de cidadania, direitos humanos, diferenças culturais, religiosas, de gênero, entre outras.

\section{Cultura e mobilidade humana: desafio contemporâneo para a Terapia Ocupacional}

A multiplicidade do panorama dos processos migratórios, de demandas e possibilidades diversas, exige também um olhar atento dos diversos setores da sociedade, das políticas públicas e também dos profissionais que se deparam com essa demanda em seus processos de trabalho. Assim, o terapeuta ocupacional, que também dialoga com questôes da contemporaneidade e com processos de ruptura de redes de suporte, violação de direitos humanos, e que ao mesmo tempo também propóe novas possibilidades de projetos de vida, inserção social, econômica, política e cultural, é um dos tantos profissionais imprescindíveis para se inserir nesse contexto.

A temática da migração tem encontrado ressonância em trabalhos e reflexóes na terapia ocupacional há vários anos, sendo construçôes e diálogos importantes que abrem novas possibilidades e desafios para o campo da profissão. Há pesquisadores dedicando-se às questóes circundadas à mobilidade humana, sejam no âmbito das migraçôes, situações de refúgio ou de descolamentos devido às catástrofes naturais. $\mathrm{Na}$ literatura internacional, os estudos têm se voltado principalmente para a educação e saúde, saúde mental e saúde da mulher (DYCK, 1992; KINÉBANIAN; STOMPH, 1992; POOREMAMALI; PERSSON; EKLUND, 2011; SANTOS-TAVARES; THORÉN-JÖNSSON, 2013; WERGE-OLSEN; VIK, 2012). Soma-se a estes o trabalho de Pizzi (2015) sobre modelo de intervenção em comunidades atingidas pelo furacão Sandy em 2012, nos Estados Unidos. No Canadá, a migração na interface com saúde e trabalho tem sido preocupação de Lilian Magalhães, terapeuta ocupacional docente da University of Western Ontario. Em publicação recente, Davy et al. (2014) discutiram a aplicaçáo da metodologia dos Mapas Corporais com refugiados.

Aqui no Brasil existem, igualmente, publicaçóes apontando para uma demanda social crescente. Em 2007, Sato, Barros e Santos (2007) assinalavam a presença crescente de africanos em albergues na cidade de São Paulo, vindos de diferentes lugares e em contextos de violação de direitos humanos, sobretudo de países com conflitos armados. A mobilidade humana foi, igualmente, abordada em estudos de Barros e Galvani (No prelo); Savadogo (2014), Barros (2010, 2015), Pierote-Silva (2014), em diferentes vertentes de pesquisa, tematizando, respectivamente, a mobilidade estudantil, religiosidade e busca de conhecimento, e a reflexão sobre mobilidade e dos direitos humanos. Nestes estudos, a cultura enquanto modo de vida, formas relacionais, ética, estética e de expressóes do sagrado que criam sentidos, pertencimentos e identidades, é eixo organizador das reflexôes e das metodologias de açáo e construção de conhecimento em terapia ocupacional.

Desde 2011, a parceria da Casa das Áfricas ${ }^{2}$ com o Projeto Metuia $^{3}$ (Núcleo USP) tem conduzido, no campo da cultura, educação e dos direitos humanos, diferentes iniciativas de estudos, extensão universitária, formação e debates sobre mobilidade humana, diversidade cultural, artes e migração africana em São Paulo. Os trabalhos têm pautado a necessidade de discussão e enfrentamento da questão da diferença, da diversidade, do combate ao racismo e da afirmaçáo dos direitos humanos, com base no reconhecimento dos pertencimentos e valores multiculturais.

É importante ressaltar que o artigo 5 da Resolução no 406 do Conselho Federal de Fisioterapia e Terapia Ocupacional (CONSELHO..., 2011) prevê a ação da 
terapia ocupacional nos Contextos Sociais nas áreas de migração e deslocamento. Assim, esta pesquisa ${ }^{4}$ integra a construção teórico-prática do Projeto Metuia-USP/UFSCar neste campo realizada por meio da parceria entre esse grupo interinstitucional e a Casa das Áfricas. Nesse contexto, vem-se fomentando discussóes sobre migração e mobilidade africana e, ao mesmo tempo, empreendido açóes práticas de suporte social, educacional e cultural a imigrantes africanos/as (PIEROTE-SILVA et al., 2014).

A Casa das Áfricas, junto com o Projeto Metuia, participou na formulação de propostas e articulação com os movimentos sociais, através da presença ativa nas audiências públicas e conferências (municipais, estaduais e federais). Uma frente assumida pela parceria foi a reivindicação e mobilização dos estudantes migrantes e de seus direitos nas pautas dos encontros, além do acompanhamento realizado com alguns deles para questôes de validação de diplomas. A Casa também conseguiu, junto com os demais atores, inserir a presença de africanos nesse debate, até entâo marcada principalmente pelos latino-americanos. A participação dos estudantes e dos bolsistas dos projetos de extensão vinculados ao curso de graduação nesse cenário foi momento importante para formação e discussão da inserção social da terapia ocupacional nesses novos contextos.

É possível pensar essa discussão como ponto de partida para o diálogo com a temática da migração na terapia ocupacional. Como o entendimento de uma perspectiva ampla, do panorama da migração na cidade, como a configuração da política pública migratória pode e deve articular-se também com uma perspectiva singular, da vida cotidiana de cada sujeito, de projetos de vidas, das necessidades de cada um. É nessa interface que podemos pensar nas proposiçóes da terapia ocupacional social também plurais, permeadas por olhares coletivos e singulares, nesses vários espaços de significação da vida:

Os processos de açáo em terapia ocupacional social tornam-se espaços sociais de negociação cultural e relacional, de produção ou de facilitação de participação da pessoa na vida coletiva, na elaboraçáo de projetos de vida e no sentimento de pertencimento e, náo podem ser compreendidos através de separações e disjunções. A ação do terapeuta ocupacional, ela mesma, permanece em movimento constante (BARROS, 2004, p. 92).

A terapia ocupacional social tem se deparado com essas novas dinâmicas na cidade, rearranjos plurais nos cenários de vida dos imigrantes e se questionando como essas pessoas chegam à cidade, como se inserem nas questóes de trabalho, nas trocas sociais e econômicas, como acessam os diversos serviços, como tecem suas redes de relaçóes. Barros (2004) aponta que é preciso buscar equacionamentos singulares inseridos na produção de significados e na negociação cultural, repensando e repropondo novas formas de interlocução, que abarquem proposiçôes singulares e também coletivas. Ao propor essas possibilidades singulares em terapia ocupacional, faz-se necessária uma reflexão sobre cultura, alteridade, coabitação da diferença, uma vez que o processo migratório tem desdobramentos não apenas no âmbito da política e dos direitos humanos, mas também nos serviços, cultura, trabalho, relaçóes sociais, redes de suporte, etc.

É nosso desafio atual promover um difícil equilíbrio entre ética e saber, entre ação técnica e compreensão sócio-antropológica, entre subjetividade e necessidade. Trata-se, sobretudo, de aprender a levantar hipóteses para interpretação da realidade que se apresenta, entendendo que o nosso é um dos saberes em ação, não o único e nem tão pouco definitivo (BARROS; GHIRARDI; LOPES, 1999, p. 72).

Para Geertz (1989), a cultura é uma teia de significados entre o homem, o homem entre si e com a natureza, e sua análise deve ser uma ciência interpretativa desses sistemas simbólicos, e náo meramente experimental. Ao falar-se em cultura, é imprescindível também a noção de cultura como direito e princípio garantido pela Unesco, conforme já citado anteriormente. Boaventura de Sousa Santos (1997) afirma que só com o diálogo intercultural é possível novas possibilidades e exigências emancipatórias. Assim, o multiculturalismo está imbricado com a noção de alteridade e da coabitação da diferença. Só assim é possível conceber açôes que dialoguem com essas questōes e também em açóes políticas e igualitárias que respeitem essa diversidade e multiplicidade.

Aqui também a noção de atividade vai ser redefinida e ganha múltiplos significados, sendo também expressóes de identidade, no que Barros (2004) chama de "[...] instrumento para emancipação alimentado pela dimensão sócio-política, cultural e afetiva de pessoas, de grupos e de comunidades" (BARROS, 2004, p. 95). Atividades essas que possam redimensionar e potencializar os vários espaços de significação. Tomamos aqui como reflexão a discussão de Barros et al. (2013) sobre os espaços de significaçấo na Terapia Ocupacional Social: cultura (exigência existencial da produção de sentido), economia (dimensões múltiplas de 
produção de vida) e política (fazer político como ação comum). Os autores mostram que são nesses espaços que se articulam as redes de pertencimento, que se dá a interpretação do real e que a partir do fortalecimento dessas dimensóes podemos pensar as atividades em terapia ocupacional.

Elas (atividades) só adquirem o caráter de atividade de significação, em nosso entender, quando e enquanto expressarem sentidos em contextos social e historicamente adequados, ou seja, quando possam permitir a construção de laços sociais, de redes de relações em espaços de significação, sejam eles culturais, políticos, econômicos ou outras possibilidades de articulação de identidades coletivas e de potencialidades singulares (BARROS et al., 2013, p. 592).

Frantz Fanon realçou a importância de cultura aberta e espontânea "com sistemas de referência de determinado grupo social, a partir dos seus valores culturais, linguagem, vestuário, técnicas, etc." (FANON, 1980, p. 36). Essa abertura está no centro do cosmopolitismo contemporâneo em suas dimensóes múltiplas dos diversos arranjos das atividades significativas, das expressôes estéticas e criativas, do trabalho, das redes de relação que modelam constantemente a cidade. Em suas trajetórias, circuitos e linguagens, as pessoas criam e redesenham inscriçôes sensíveis, inovam as dinâmicas de trabalho e as relaçôes sociais, ampliam o universo religioso e político, além dos hábitos de vestimenta, comida, formas associativas, estéticas, lazer, festas, em grande pluralidade de modos de viver. Amílcar Cabral (1980), por sua vez, considera que a cultura é expressão "mais ou menos conscientizada” (CABRAL, 1980, p. 56) das atividades econômicas, políticas e das relaçôes. Nesse sentido, as políticas públicas, assim como a remodelação de ação técnico-profissional, voltadas para a questão da mobilidade humana, devem ser dialogadas e inscritas indiscutivelmente como dinâmica cultural, sem esquecer sua ancoragem nos direitos humanos como princípio fundamental e desafio constante.

As atividades em terapia ocupacional compóem-se nos vários cenários de vida das pessoas, grupos ou comunidade em sua pluriculturalidade e em entrelaçamentos novos e ressignificados. Elas são mobilizadas para a inscrição nos novos espaços existenciais, políticos e de criação de economia de vida. Enfim, o terapeuta ocupacional abre-se intelectualmente para atentar para tais processos em constante movimento e em ressignificação para trabalhar em espaços dinâmicos da mobilidade humana com suas possiblidades plurais, tanto relacionais como econômicas, e também linguísticas, literárias, poéticas e linguagens culturais. Aqui a cultura é, mais uma vez, motor da história e nela repousa os sentidos da atividade.

\section{Movências contemporâneas: pluralidade cultural e direitos humanos}

A legitimidade dos direitos humanos, segundo Boaventura de Sousa Santos (1997), só é possível no diálogo histórico e intercultural. Além disso, a Organização das Naçóes Unidas, por meio da Unesco, assumiu a diversidade cultural como direito a partir da perspectiva do patrimônio comum da humanidade, do pluralismo cultural e como fator de desenvolvimento (ORGANIZAÇÃO..., 2002).

Tais entendimentos fundamentam a necessidade de reflexão aprofundada sobre os processos migratórios em duas dimensôes, a fim de repensar tanto a ação profissional como a formação. A primeira é relativa à necessidade de rever conceitos e dinâmicas de atuação no contexto da construção de política transversal e transdisciplinar de atenção às populaçóes migrantes. Assistentes sociais, psicólogos, educadores, advogados, antropólogos, historicamente já trabalham com a questão. O terapeuta ocupacional, seja no campo da assistência social, educação, saúde, cultura ou no campo jurídico, precisa incluir essa pauta na formaçáo acadêmica, na reflexão sobre prática profissional e na construção do conhecimento. É fundamental, portanto, que a terapia ocupacional dialogue com essas novas dinâmicas, criando iniciativas de atuação e de formação que trabalhem a pluralidade cultural, social e de vida em interação e movimento próprias a essas novas realidades e movências da contemporaneidade.

A segunda dimensão vincula-se à construção das políticas públicas de garantia de direitos das populaçóes migrantes que incidem diretamente na vida cotidiana, no fazer e na produção de sentido. Muitas questóes aqui levantadas sinalizam para a necessidade de nova agenda de pesquisa sobre os desdobramentos da mobilidade na vida cotidiana, econômica, política e cultural de mulheres, homens, crianças, adultos e idosos/as que precisam de suporte no âmbito da terapia ocupacional para a reorganizaçáo de seus fazeres significativos, além do reconhecimento e interlocução de suas práticas culturais, formas expressivas e linguagens artísticas. Esperamos que a continuidade das pesquisas possa ampliar a discussão em torno das narrativas singularizadas, sobretudo de mulheres e crianças. 


\section{Referências}

ASSOCIAÇÃO PALOTINA. Disponível em: <http:// palotinas.com.br/>. Acesso em: 02 out. 2015.

BARROS, D. D. et al. Cultura, economia, política e saber como espaços de significação na Terapia Ocupacional Social: Reflexóes sobre a experiência do Ponto de Encontro e Cultura. Cadernos de Terapia Ocupacional da UFSCar, São Carlos, v. 21, n. 3, p. 583-594, 2013.

BARROS, D. D. Terapia ocupacional social: o caminho se faz ao caminhar. Revista de Terapia Ocupacional da Universidade de São Paulo, São Paulo. v. 15, n. 3, p. 90-97, 2004.

BARROS, D. D. Liens ville-village et changements sociaux face à la migration saisonnière. Le mouvement de personnes entre Songho (Région Dogon) et Bamako, Mali. Antropos, Fribourg, v. 105, p. 471-488, 2010.

BARROS, D. D. L'activité humaine dans l'économie de la vie: le sens dans l'histoire et la culture. In: MOREL-BRAQ, M.; TROURÉ, E.; OFFESTEIN, E. (Org.). L'activité humaine: un potentiel pour la santé? Paris: ANFE/de Boeck Solal Paris, 2015. p. 283-290.

BARROS, D. D.; GALVANI, D. Terapia Ocupacional Social e suas movências: reflexôes sobre práticas que renovam e ampliam horizontes. In: CAVALCANTI, C.; GALVÃO, A. (Org.). Terapia Ocupacional: teoria \& prática. Rio de Janeiro: Guanabara Koogan. No prelo.

BARROS, D. D.; GHIRARDI, M. I. G.; LOPES, R. E. Terapia Ocupacional e sociedade. Revista de Terapia Ocupacional da Universidade de São Paulo, São Paulo. v. 10, n. 2-3, p. 69-74, 1999.

BONASSI, M. Migrantes ilegais: a vida e a lei. Travessia - Revista do Migrante, São Paulo, ano X, n. 29, p. 34-41, 1998.

BRASIL. Lei no 6.815, de 19 de agosto de 1980. Define a situação jurídica do estrangeiro no Brasil, cria o Conselho Nacional de Imigraçáo. Diário Oficial da República Federativa do Brasil, Brasília, DF, 22 ago. 1980.

BRASIL. Comissão de Relaçôes Exteriores e Defesa Nacional. Projeto de Lei de Migração no 288 de 2013. Brasília, 2013a. Disponível em: <http://www.senado.gov.br/ atividade/materia/detalhes.asp?p_cod_mate $=113700>$. Acesso em: 10 maio 2015.

BRASIL. Ministério da Justiça. Relatório Nacional sobre Tráfico de Pessoas: dados. Brasília: Escritório das Naçôes Unidas sobre Drogas e Crime, 2013b. Disponível em: $<$ http://www.justica.gov.br/sua-protecao/trafico-de-pessoas/publicacoes>. Acesso em: 07 out. 2015.

CABRAL, A. A cultura nacional. In: COMITINI, C. $A$ arma da teoria. Rio de Janeiro: Codecri, 1980. p. 53-92.

CÁRITAS BRASILEIRA. Brasília, 2013. Disponível em: <http://caritas.org.br/projetos/programas-caritas/ refugiados $>$. Acesso em: 02 out. 2015.
COHEN, R. Global diásporas - an introduction. London: UCL Press, 1999.

CONSELHO FEDERAL DE FISIOTERIA E TERAPIA OCUPACIONAL - COFFITO. Resolução No 406, de 7 de novembro de 2011. Disciplina a Especialidade Profissional Terapia Ocupacional nos Contextos Sociais e dá outras providências. Diário Oficial da Uniāo, Brasília, DF, 24 nov. 2011. Disponível em: <http: <http://www.coffito.org.br/site/index.php/home/ resolucoes-coffito/485-resolucao-n-406-2011-disciplina-a-especialidade-profissional-terapia-ocupacional-nos-contextos-sociais-e-da-outras-providencias.html>. Acesso em: 10 abr. 2015.

DAVY, C. et al. Aspects of the resilience and settlement of refugee youth: a narrative study using body maps/Aspectos da resiliência e da integração social de jovens refugiados: um estudo narrativo usando mapas corporais. Cadernos de Terapia Ocupacional da UFSCar, São Carlos, v. 22, n. 2, p. 231-241, 2014.

DYCK, I. Managing chronic illness: an immigrant woman's acquisition and use of health care knowledge. American Journal of Occupational Therapy, Montgomery, v. 46, p. 696-705, 1992.

FANON, F. Racismo e cultura. In: FANON, F. Em defesa da revolução africana. Lisboa: Livraria Sá da Costa, 1980. p. 35-48.

GEERTZ, C. A interpretação das culturas. Rio de Janeiro: LTC, 1989.

INSTITUTO DE REINTEGRAÇÃO DO REFUGIADO - ADUS. São Paulo, 2015. Disponível em: <http:// www.adus.org.br/>. Acesso em: 02 out. 2015.

KALY, A. P. O Ser Preto africano no "paraíso terrestre" brasileiro. Um sociólogo senegalês no Brasil. Lusotopie, Bordeaux, p. 105-121, 2001.

KINÉBANIAN, A.; STOMPH, M. Cross-cultural Occupational Therapy: a critical reflection. American Journal of Occupational Therapy, Montgomery, v. 46, n. 8, p. 751-757, 1992.

KRIEGER, C. A. A consolidação do direito internacional humanitário: precedente do Comitê Internacional da Cruz Vermelha e a contribuição definitiva da Convenção de Roma de 1998. 2002. 509 f. Tese (Doutorado em Direito) - Universidade Federal de Santa Catarina, Florianópolis, 2002.

LÚCIO, V. Estrangeiros no Brasil: Missão Paz em São Paulo acolhe imigrantes até a legalizaçáo. Ciência e Cultura, São Paulo, v. 67, n. 2, p. 51-52, 2015.

MISSÃO PAZ. São Paulo, 2015. Disponível em: <http:// www.missaonspaz.org/\#!paroquias/c1719>. Acesso em: 02 out. 2015.

NAIME, J. O perfil da migração africana. Resenha. Conjuntura Internacional, Belo Horizonte, p. 1-6, 2006. Disponível em: <http://www.pucminas.br/imagedb/ 
conjuntura/CNO_ARQ_NOTIC20061206142629. pdf>. Acesso em: 10 jun. 2015.

O ESTRANGEIRO. São Paulo terra dos sonhos e do preconceito. 2014. Disponível em: <http://oestrangeiro. org/2014/01/30/sao-paulo-terra-dos-sonhos-e-do-preconceito/>. Acesso em: 15 maio 2015.

ORGANIZAÇÃO DAS NAÇÓES UNIDAS - ONU. Declaração Universal dos Direitos do Homem de 1948. 2009. Disponível em: <http://www.dudh.org.br/wp-content/uploads/2014/12/dudh.pdf>. Acesso em: 15 maio 2015.

ORGANIZAÇÃO DAS NAÇÓES UNIDAS - ONU. Declaração Universal sobre a Diversidade Cultural. 2002. Disponível em: <http://unesdoc.unesco.org/ images/0012/001271/127160por.pdf>. Acesso em: 15 maio 2015.

PAIVA, O. C. Territórios da migração na Cidade de São Paulo: afirmação, negação e ocultamentos. In: TEIXEIRA, E.; BRAGA, A. M. C.; BAENINGER, R (Org.). Migraçôes: implicaçóes passadas, presentes e futuras. Marília: Oficina Universitária; São Paulo: Cultura Acadêmica, 2012. p. 167-186.

PATARRA, N. L. O Brasil: país de imigraçáa? E-metropolis, Rio de Janeiro, ano 3, n. 9, p. 6-18, 2012. Disponível em: <http://www.emetropolis.net/download/edicoes/emetropolis_n09-ed.pdf>. Acesso em: 10 nov. 2015.

PIEROTE-SILVA, V. A contemporânea migração a fricana para a cidade de São Paulo: garantia de direitos, políticas públicas e diversidade. 2014. 46 f. Monografia (Especialização em Terapia Ocupacional: campos de intervenção e perspectivas de inovaçôes da prática) - Universidade de São Paulo, São Paulo, 2014.

PIEROTE-SILVA, V. et al. Migração africana: diversidade e mobilidade como desafios contemporâneos para a Terapia Ocupacional Social. Cadernos de Terapia Ocupacional da UFSCar, São Carlos, v. 22, p. 237-244, 2014. Suplemento Especial 2.

PISCITELLI, A. Interseccionalidades, categorias de articulação e experiências de migrantes brasileiras. Sociedade e Cultura, Goiânia, v. 11, n. 2, p. 263-274, 2008.

PIZZI, M. A. Hurricane Sandy, Disaster Preparedness, and the Recovery Model. American Journal of Occupational Therapy, Montgomery, v. 69, n. 4, p. 751-757, 2015.

POOREMAMALI, P.; PERSSON, D.; EKLUND, M. Occupational therapists' experience of working with immigrant clients in mental health care. Scandinavian Journal of Occupational Therapy, Stockholm, v. 18, n. 2, p. 109-121, 2011.

REDE BRASIL ATUAL - RBA. Brasil tem 7,7 mil refugiados, vindos de 81 paises, aponta Ministério da Justiça. Sấo Paulo, 2015. Disponível em: <http://www.redebrasilatual.com.br/cidadania/2015/06/brasil-tem-7-7-milhoes-refugiados-vindos-de-81-paises-aponta-ministerio-da-justica-1372.html>. Acesso em: 10 jun. 2015.
SANTOS, B. S. S. Por uma concepção multicultural de direitos humanos. Revista Crítica de Ciências Sociais, Coimbra, n. 48, p. 11-32, 1997.

SANTOS-TAVARES, I.; THORÉN-JONSSON, A. L. Confidence in the future and hopelessness: Experiences in daily occupations of immigrants with late effects of polio. Scandinavian Journal of Occupational Therapy, Stockholm, v. 20, n. 1, p. 9-20, 2013.

SÃO PAULO (Município). Decreto no 42.380, de 11 de setembro de 2002. Aprova o Regimento Interno da Comissão Municipal de Direitos Humanos. Diário Oficial do Município, São Paulo, SP, 11 set. 2002. Disponível em: <http://www3.prefeitura.sp.gov.br/ cadlem/secretarias/negocios_juridicos/cadlem/integra. asp?alt $=12092002 \mathrm{D} \% 20423800000>$. Acesso em: 02 out. 2015.

SÃO PAULO (Município). Comissão Municipal de Direitos Humanos. Relatório 2005. São Paulo, 2005. Disponível em: <http://www.dhnet.org.br/dados/ relatorios/r_cmdh/r_2005_sp_2cmdh.pdf>. Acesso em: 02 out. 2015.

SÃO PAUlO (Município). Comissão Municipal de Direitos Humanos. Relatório 2007. São Paulo, 2007. Disponível em: <http://www.dhnet.org.br/dados/ relatorios/r_cmdh/r_2007_sp_cmdh.pdf>. Acesso em: 02 out. 2015.

SÃO PAULO (Município). Secretaria Municipal de Direitos Humanos e Cidadania. Documento Final da I Conferência Municipal de Politicas para Imigrantes de São Paulo. São Paulo, 2013.

SÃO PAULO (Município). Coordenação de Políticas para Migrantes. São Paulo, 2015a. Disponível em: <http:// www.prefeitura.sp.gov.br/cidade/secretarias/direitos_humanos/migrantes/coordenacao/index.php? $\mathrm{p}=156223>$. Acesso em: 02 out. 2015.

SÃO PAULO (Município). Coordenação de Políticas para Migrantes. Centro de Referência e Acolbida para Imigrantes. São Paulo, 2015b. Disponível em: <http://www. prefeitura.sp.gov.br/cidade/secretarias/direitos_humanos $/$ migrantes $/$ crai $/$ index.php? $\mathrm{p}=186973>$. Acesso em: 02 out. 2015.

SÃO PAULO (Município). Secretaria Municipal de Direitos Humanos. São Paulo, 2015c. Disponível em: $<$ http://www.prefeitura.sp.gov.br/cidade/secretarias/ direitos_humanos/a_secretaria/index.php?p=148581>. Acesso em: 02 out. 2015.

SÃO PAULO (Estado). Secretaria da Justiça e da Defesa da Cidadania. Inaugurada a primeira casa de passagem para refugiados do país. São Paulo, 2015d. Disponível em: <http://www.justica.sp.gov.br/portal/site/SJDC/ menuitem.b1a98ae13ac6514354f160f4390f8ca0/?vgne xtoid=6aa6648792168410 VgnVCM1000008936c80a RCRD\&vgnextfmt=default $>$. Acesso em: 02 out. 2015.

SATO, M.; BARROS, D. D.; SANTOS, A. S. A. Da África para albergues públicos: africanos na Casa do 
Migrante em São Paulo. Estudos Afro-Asiáticos, Rio de Janeiro, v. 29, n. 1-3, p. 29-62, 2007.

SAVADOGO, P. B. A. H. Desafios de jovens muçulmanos em Burquina Faso no retorno de estudo em países de língua árabe: entre vulnerabilidades e a reconstrução da cidadania. 2014. 110 f. Dissertação (Mestrado em Terapia Ocupacional) - Universidade Federal de São Carlos, São Carlos, 2014.

SAYAD, A. Imigração ou os paradoxos da alteridade. São Paulo: Edusp, 1998.

SERVIZIO MISSIONARIO GIOVANI - SERMIG. Fraternidade da esperança. 2015. Disponível em: <http:// www.sermig.org/>. Acesso em: 02 out. 2015.

SERRANO, M. L. E. "África” em Río de Janeiro: una cartografía sobre lainmigración contemporánea. $M E$ MORIAS - Revista digital de Historia y Arqueología desde el Caribe colombiano, Barranquilla, v. 8, n. 15, p. 272302, 2011.
SOARES, W.; LOBO, C.; MATOS, R. Mobilidade espacial dos imigrantes estrangeiros no Brasil: 1991/2010. Revista Interdisciplinar de Mobilidade Humana, Brasília, v. 23, n. 44, p. 191-205, 2015.

TELES, T. C. Nzambi ikale ni enhe! Histórias de vida de imigrantes angolanos em São Paulo. 2013.301 f. Dissertação (Mestrado em História Social) - Universidade de São Paulo, São Paulo, 2013.

UNESCO. Declaração Universal sobre a Diversidade Cultural. 2002. Disponível em: <http://unesdoc.unesco. org/images/0012/001271/127160por.pdf>. Acesso em: 02 out. 2015.

WERGE-OLSEN, I.; VIK, K. Activity as a tool in language training for immigrants and refugees. Scandinavian Journal of Occupational Therapy, Stockholm, v. 19, n. 6, p. 530-541, 2012.

\section{Contribuição dos Autores}

Miki Takao Sato e Denise Dias Barros contribuíram para a concepção do texto, organização dos dados, discussão, redação e revisão final do texto. As autoras aprovaram a versão final do texto.

\section{Notas}

${ }^{1}$ Afeganistão (desde 2001), República Democrática do Congo (1994-2003), Eritreia e Etiópia (1998-2003), Iraque (2003), Líbia (2011) entre outros.

2 Instituto cultural, de formação e de estudos sobre sociedades africanas, localizada em São Paulo.

${ }^{3}$ Grupo interinstitucional de estudos, formação e ações pela cidadania de crianças, adolescentes e adultos em processos de ruptura das redes sociais de suporte.

${ }^{4} \mathrm{O}$ material é parte de pesquisa realizada no contexto do Programa de Mestrado e do Projeto Metuia, integrando o projeto Brasil \& Áfricas: artes, culturas, mobilidade e direitos humanos, no contexto da linha de pesquisa Redes Sociais e Vulnerabilidade, do Programa de Pós-graduação em Terapia Ocupacional da UFSCar. 